\title{
ANALISIS KEMAMPUAN PEMECAHAN MASALAH SISWA PADA PEMBELAJARAN SPLDV BERBASIS STEM
}

\author{
Iis Juniati Lathiifah ${ }^{1}$, Eka Rachma Kurniasi ${ }^{2}$ \\ ${ }^{1,2}$ Prodi Pendidikan Matematika, Universitas Muhammadiyah Bangka Belitung, Jl. KH. Ahmad Dahlan 52, \\ Kabupaten Bangka Tengah, Provinsi Kepulauan Bangka Belitung, 33684, Indonesia \\ iis.juniatilathiifah@stkipmbb.ac.id
}

\begin{abstract}
The aim of this research was to analyze students's problem solving abilities on the Sistem Persamaan Linier Dua Variabel STEM based worksheet. This research is a qualitative descriptive study. Data obtained from the analysis of the results of the worksheets done by students and observations during the implementation of learning. Analysis of students' problem solving abilities was assessed based on problem solving indicators, namely: (1) write what facts are known (2) write what you need to know (3) identify the problem (4) create action plans and (5) make the right finish. The five indicators are then made into eight descriptors. The results of the analysis carried out indicated that as many as $97.78 \%$ of students could determine what facts were known, $88.89 \%$ of students could determine what was known, $95.56 \%$ of students could identify problems, $88.89 \%$ of students could make action plans and as many as $85.55 \%$ of students can make the correct solutions. So that the average student problem solving ability is $91.334 \%$. This shows that the students' mathematical problem solving skills after working on the STEM-based activity sheet are very good.
\end{abstract}

Keywords: Analysis, Problem Solving Skill, SPLDV, STEM

\begin{abstract}
Abstrak
Salah satu dari tujuan dalam proses pembelajaran adalah pemecahan masalah. Namun berbagai penelitian menunjukkan bahwa kemampuan pemecahan masalah matematis siswa belum sesuai dengan yang diharapkan. Materi Sistem Persamaan Linier Dua Variabel sangat berkaitan dengan kehidupan sehari-hari yang menuntut suatu penyelesaian. Pendekatan STEM merupakan salah satu pembelajaran yang dapat mengoptimalkan kemampuan pemecahan masalah siswa. Karena itu penelitian dilakukan untuk menganalisis kemampuan pemecahan masalah siswa terhadap lembar kerja Sistem Persamaan Linier Dua Variabel berbasis STEM. Penelitian ini merupakan penelitian deskriptif kualitatif dimana data diperoleh dari analisis hasil lembar kerja yang dikerjakan siswa dan observasi saat pelaksanaan pembelajaran. Analisis kemampuan pemecahan masalah siswa dinilai berdasarkan indikator pemecahan masalah yakni (1) menuliskan fakta apa yang diketahui (2) menuliskan apa yang perlu diketahui (3) mengidentifikasi masalah (4) membuat rancangan tindakan dan (5) membuat penyelesaian yang tepat. Ke lima indikator ini kemudian dibuat menjadi delapan buah deskriptor. Hasil analisis yang dilakukan didapat bahwa sebanyak 97,78\% siswa yang dapat menentukan fakta apa yang diketahui, 88,89\% siswa dapat menentukan apa yang diketahui, 95,56\% siswa dapat mengidentidikasi masalah, $88,89 \%$ siswa dapat membuat rancangan tindakan dan sebanyak $85,55 \%$ siswa dapat membuat penyelesaian dengan tepat. Sehingga rata-rata kemampuan pemecahan masalah siswa adalah $91,334 \%$. Hal ini menunjukkan bahwa kemampuan pemecahan masalah matematika siswa setelah mengerjakan lembar kerja berbasis STEM adalah sangat baik.
\end{abstract}

Kata kunci: Analisis, Kemampuan Pemecahan Masalah, SPLDV, STEM

\section{PENDAHULUAN}

Kemampuan pemecahan masalah merupakan salah satu faktor capaian untuk tercapainya tujuan pembelajaran matematika (Hidayat \& Sariningsih, 2018). Ditinjau dari aspek kurikulum, pemecahan masalah merupakan salah satu tujuan dalam proses pembelajaran (Cahyani \& Setyawati, 2017). Namun hasil penelitian terdahulu banyak yang menunjukkan bahwa kemampuan pemecahan 
masalah matematis siswa belum sesuai dengan yang diharapkan (Sumartini, 2018). Karena itu, penting sekali memastikan siswa dapat memahami proses pemecahan masalah dari pembelajaran yang telah dilaksanakan.

Matematika adalah subjek yang penting dalam kehidupan manusia (Siregar, 2017). Karena itu matematika ada di semua jenjang sekolah, mulai dari pra sekolah hingga di bangku kuliah. Salah satu tujuan dari belajar matematika adalah agar siswa mempunyai kemampuan atau keterampilan dalam memecahkan masalah (Widjajanti, 2009). Masalah adalah suatu pertanyaan yang menuntut jawaban dengan prosedur tertentu sehingga memerlukan penalaran berfikir untuk menyelesaikannya (Farida, 2015). Keterampilan memecahkan masalah banyak dijumpai pada soal cerita. Materi Sistem Persamaan Linier Dua Variabel (SPLDV) sangat berkaitan dengan kehidupan sehari-hari (Arifin et al., 2016). Segala sesuatu yang berhubungan dengan kehidupan sehari-hari pasti membutuhkan penyelesaian. Dengan kemampuan memecahkan masalah, siswa menjadi terampil dalam mengumpulkan informasi, menganalisis dan meneliti kembali hasil yang telah diperoleh (Handayani, 2017).

Buku merupakan media komunikasi antara guru dan siswa (Wijayanti, 2020). Namun diperlukan guru yang kreatif untuk dapat menciptakan suasana belajar yang mendorong siswa agar kreatif pula. Diperlukan kreativitas dari guru untuk memilih sumber belajar yang sesuai dengan kebutuhan dan perkembangan siswa sehingga proses belajar lebih optimal (Lathiifah et al., 2015).

Salah satu pembelajaran yang dapat mengoptimalkan kemampuan pemecahan masalah adalah pendekatan STEM. Pendekatan STEM sangat potensial untuk melatih kemampuan siswa dalam melakukan pemecahan masalah melalui sebuah proyek yang terintegrasi dengan satu atau beberapa keilmuan lainnya (Ismayani \& Pangeran Hidayatullah No, 2016). STEM merupakan suatu pembelajaran yang mengintegrasikan antara sians, teknologi, teknik dan matematika. STEM saat ini menjadi alternatif pembelajaran yang dapat membangun generasi yang mampu menghadapi abad 21 yang penuh tantangan (Permanasari, 2016). Sehingga tujuan dari penelitian ini adalah untuk menganalisis kemampuan pemecahan masalah siswa pada pembelajaran SPLDV yang menggunakan pembelajaran berbasis STEM.

\section{METODE}

Penelitian ini merupakan penelitian kualitatif deskriptif (Bernard et al., 2018). Tujuannya adalah untuk mendeskripsikan kemampuan pemecahan masalah matematis siswa setelah belajar materi Sistem Persamaan Linier Dua Variabel (SPLDV) dengan pendekatan STEM. Berikut disajikan diagram alir penelitian 
Analisis Kemampuan Pemecahan Masalah Siswa Pada Pembelajaran Spldv Berbasis STEM, Iis Juniati Lathiifah, Eka

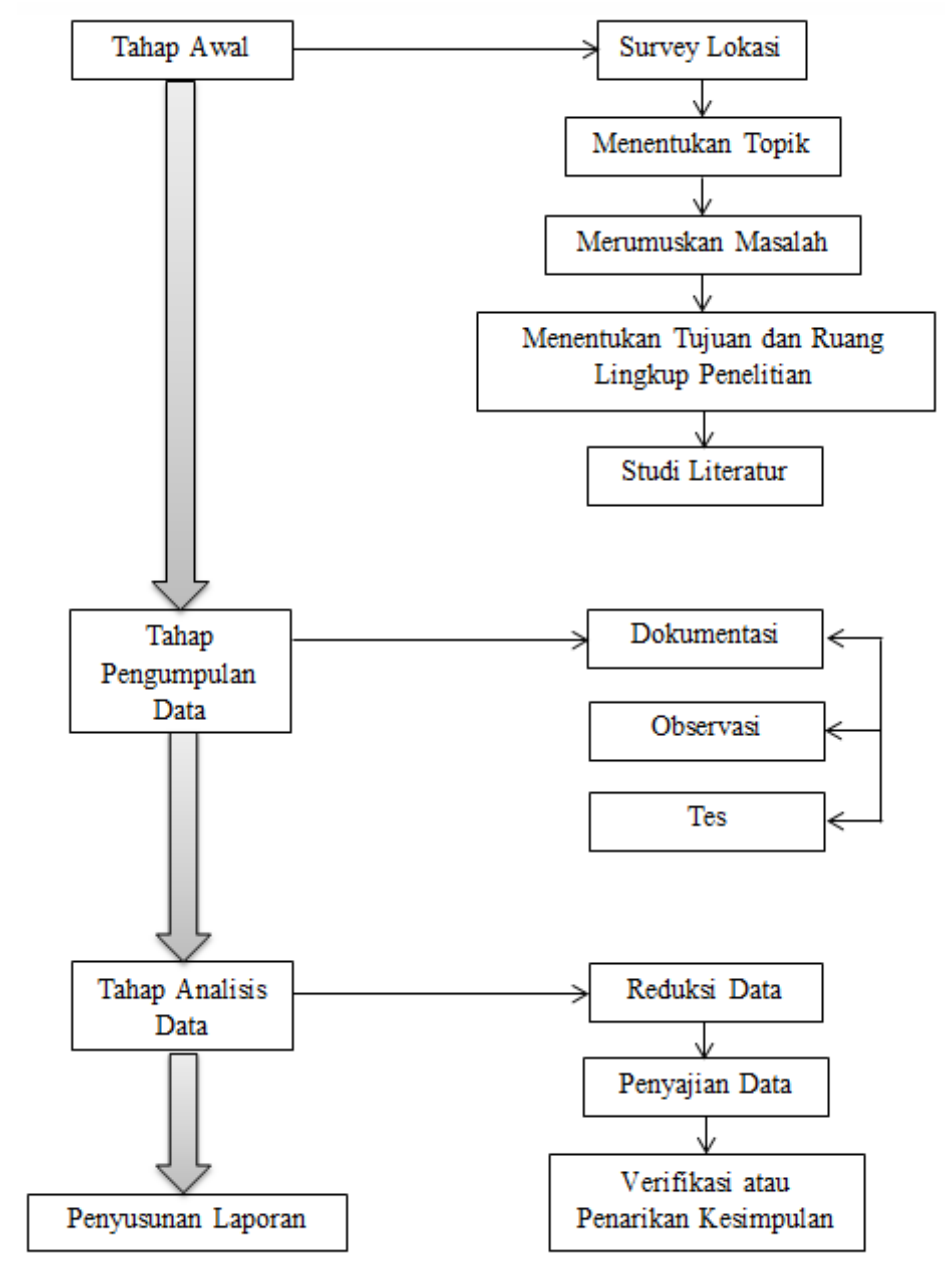

Diagram 1. Diagram alir penelitian

Pada tahap awal dilakukan survey lokasi dan subjek penelitian yaitu siswa kelas VIII SMP Negeri 3 Pangkalpinang. Penelitian dilaksanakan pada Tahun Ajaran 2020-2021 yakni pada bulan Agustus hingga September 2020. Instrumen yang digunakan adalah Lembar Kerja Siswa materi Sistem Persamaan Linier Dua Variabel dengan pendekatan STEM serta Lembar Respon Siswa. Analisis data adalah analisis hasil pembelajaran siswa menggunakan LKS berbasis STEM dan analisis hasil lembar respon siswa setelah dilaksanakan pembelajaran.

Pengumpulan data dilakukan dengan cara observasi siswa yang mengerjakan LKS berbasis STEM. Lembar kerja siswa yang digunakan dalam penelitian ini adalah lembar kerja yang sebelumnya telah divalidasi oleh tim ahli dan guru mata pelajaran matematika kelas VIII. Dari hasil validasi telah dinyatakan bahwa lembar kerja valid dan siap digunakan untuk siswa kelas VIII. Sembari observasi, dilakukan pula dokumentasi dan tes setelah siswa mengerjakan LKS.

Untuk melihat kemampuan pemecahan masalah matematis siswa, digunakan indikator pemecahan masalah yang dijabarkan lagi ke dalam delapan buah deskriptor kemudian disajikan pada tabel berikut. 


\section{Tabel 1.}

Indikator Kemampuan Siswa Memecahkan Masalah

\begin{tabular}{|l|l|}
\hline \multicolumn{1}{|c|}{ Indikator Pemecahan Masalah } & \multicolumn{1}{c|}{ Deskriptor } \\
\hline Menuliskan fakta "apa yang diketahui" & 1. Menuliskan semua fakta dari suatu permasalahan \\
\hline Menuliskan apa yang perlu diketahui & 2. Menuliskan informasi penting dari suatu masalah \\
\hline Mengidentifikasi masalah & $\begin{array}{l}\text { 3. Menuliskan apa yang menjadi pokok } \\
\text { permasalahan }\end{array}$ \\
\hline Membuat rancangan tindakan & 4. Membuat pemetaan masalah \\
& 5. Melakukan langkah penyelesaian \\
& 6. Melakukan langkah penyelesaian dengan tepat \\
\hline Membuat penyelesaian yang tepat & 7. Menarik kesimpulan \\
& 8. Menuliskan kesimpulan dengan tepat \\
\hline
\end{tabular}

Tabel 1 merupakan indikator dan deskriptor untuk menilai pengetahuan siswa dalam memecahkan setiap masalah (Lathiifah et al., 2015). Penilaian dilakukan melalui observasi pada saat siswa mengerjakan LKPD berbasis STEM. Penilaian dilakukan pada setiap deskriptor dengan cara mencentang atau memberi ceklis jika dilakukan siswa dan memberi tanda silang jika tidak dilakukan siswa. Setiap deskriptor yang dicentang diberi skor 1 sedangkan yang disilang diberi skor 0 . Untuk menentukan tingkat kemampuan pemecahan masalah siswa, rata-rata nilai yang didapat akan dikonversikan ke dalam bentuk tingkat kemampuan yang disajikan pada tabel 2. (Meutia et al., 2013):

Tabel 2.

Kategori tingkat keamampuan siswa

\begin{tabular}{|c|c|l|}
\hline No & Interval Nilai & \multicolumn{1}{|c|}{ Kategori } \\
\hline 1 & $85-100$ & Sangat Baik \\
\hline 2 & $65-84$ & Baik \\
\hline 3 & $45-64$ & Cukup Baik \\
\hline 4 & $35-44$ & Kurang Baik \\
\hline 5 & $0-34$ & Tidak Baik \\
\hline
\end{tabular}

\section{HASIL}

Penelitian ini dilaksanakan pada siswa kelas VIII SMP Negeri 3 Pangkalpinang tahun ajaran 2020/2021. Siswa diambil secara acak dari kelas VIII A hingga VIII F. Semua siswa kemudian diberikan sebuah lembar kerja materi Sistem Persamaan Linier Dua Variabel menggunakan pendekatan STEM. Lembar kerja ini telah dibuat ke dalam tiga buah kegiatan. Kegiatan 1 untuk menjawab dua buah indikator yakni menentukan unsur-unsur persamaan linier dua variabel dan 
Analisis Kemampuan Pemecahan Masalah Siswa Pada Pembelajaran Spldv Berbasis STEM, Iis Juniati Lathiifah, Eka Rachma Kurniasi

mendefinisikan sistem persamaan linier dua variabel. Kegiatan 2 untuk menjawab indikator menentukan nilai variabel dari suatu syistem persamaan linier dua variabel. Sedangkan kegiatan 3 untuk menjawab indikator menyelesaikan masalah yang berkaitan dengan sistem persamaan linier dua variabel.

Siswa kemudian diminta untuk mengerjakan lembar kerja secara individu dengan urutan dari halaman pertama agar didapat pemahaman yang baik. Berikut pada gambar 1 disajikan jawaban siswa pada kegiatan 1.

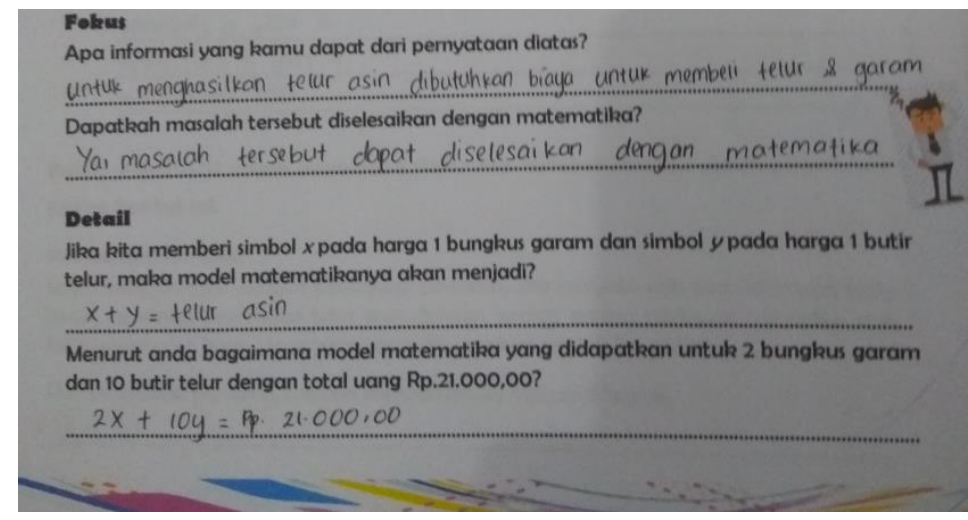

Gambar 1. Siswa dapat menuliskan fakta yang diketahui

Gambar 1 merupakan jawaban siswa yang menuliskan fakta yang diketahui dari percobaan yang dilakukan. Siswa dapat menuliskan informasi mengenai apa yang diketahui dari percobaan yang dilakukan dan menganalisis permasalahan yang terjadi.

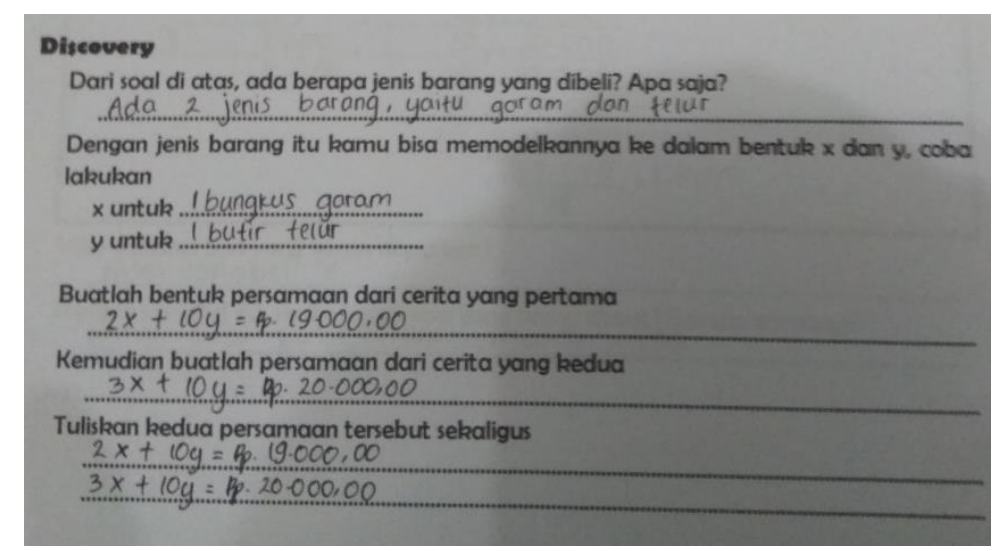

Gambar 2. Jawaban siswa saat memetakan masalah menjadi kalimat matematika

Pada gambar 2 diberikan jawaban siswa pada kegiatan 2. Terlihat bagaimana siswa dapat memetakan masalah dan membuat rancangan penyelesaian dari permasalahan yang diberikan. Siswa dapat memodelkan permasalahan yang diberikan ke dalam bentuk kalimat matematika. Meski pada kegiatan kedua disajikan dua buah cerita, namun siswa dapat membuat kalimat matematika dari masing-masing cerita sehingga menjadi bentuk persamaan linier. 


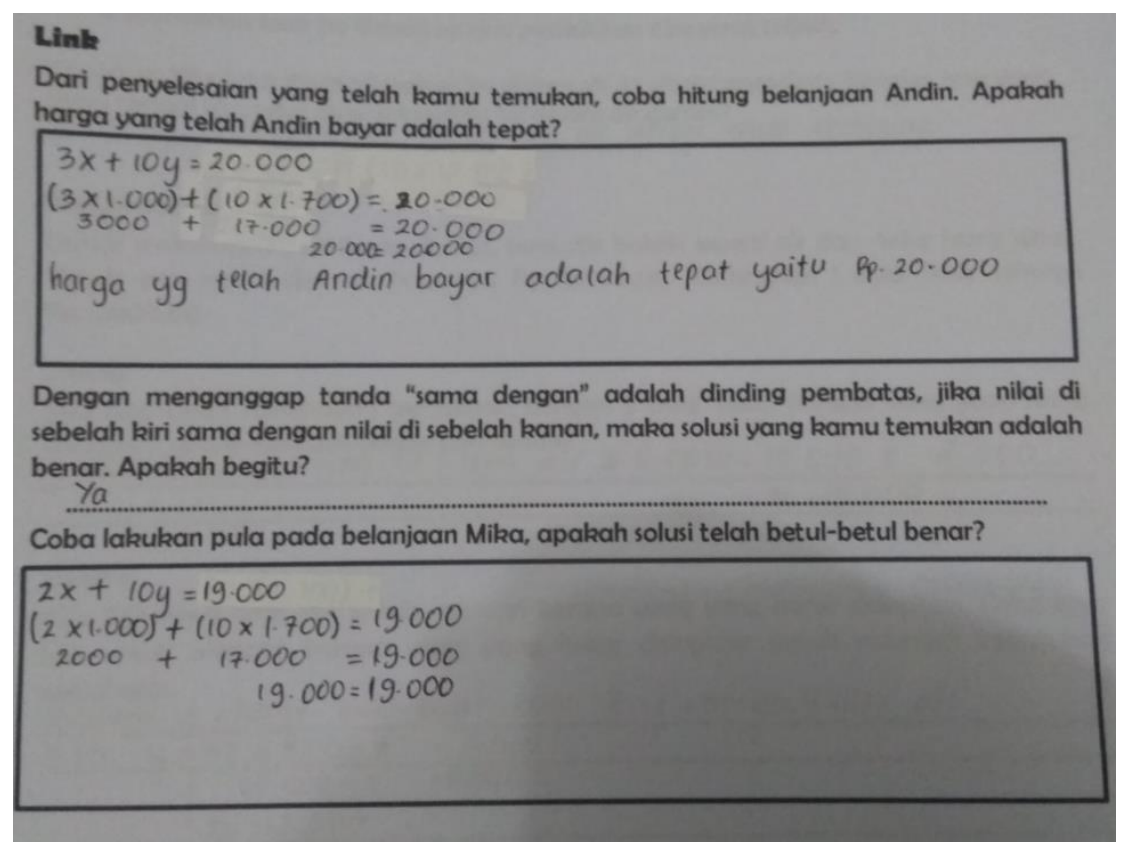

Gambar 3. Jawaban siswa untuk melihat kembali jawaban yang didapat

Pada gambar 3, siswa diminta untuk melihat kembali jawaban yang telah didapat. Proses ini merupakan bagian dari indikator penyelesaian masalah yang terakhir yaitu membuat penyelesaian yang tepat. Pada langkah ini siswa harus benar-benar yakin terhadap jawaban yang telah ditemukan yang dibuktikan dengan melihat kembali kepada penyelesaian. Dalam pembelajaran berbasis STEM, kegiatan ini ada dalam tahapan link. Disini siswa diberian kesempatan untuk mengaitkan kembali jawaban yang telah ditemukan terhadap soal yang diberikan untuk membuktikan bahwa jawaban yang telah diberikan adalah betul-betul benar.

Setelah melihat satu persatu jawaban dari siswa, kemudian dilakukan pemetaan terhadap kemampuan pemecahan masalah matematis siswa dengan mengacu kepada delapan buah deskriptor yang disiapkan. Berikut disajikan hasil kemampuan penyelesaian masalah siswa sebanyak 30 siswa dalam tiga buah kegiatan untuk masing-masing deskriptor.

\section{Tabel 3.}

Kemampuan Pemecahan Masalah Tiap Deskriptor.

\begin{tabular}{|c|c|c|c|c|c|c|c|c|c|}
\hline \multirow{2}{*}{$\begin{array}{c}\text { Indikator } \downarrow \\
\text { Pertemuan } \rightarrow\end{array}$} & \multirow{2}{*}{$\begin{array}{l}\text { Deskri } \\
\text { ptor }\end{array}$} & \multicolumn{3}{|c|}{ Frekuensi } & \multicolumn{3}{|c|}{ Persentase } & \multirow{2}{*}{$\begin{array}{c}\text { Rata- } \\
\text { rata }\end{array}$} & \multirow{2}{*}{\begin{tabular}{|c|}
$\begin{array}{c}\text { Rata- } \\
\text { rata }\end{array}$ \\
$\begin{array}{c}\text { Per- } \\
\text { indikator }\end{array}$ \\
\end{tabular}} \\
\hline & & 1 & 2 & 3 & 1 & 2 & 3 & & \\
\hline $\begin{array}{l}\text { Menuliskan fakta "Apa } \\
\text { yang diketahui", }\end{array}$ & 1 & 28 & 30 & 30 & $93,33 \%$ & $100 \%$ & $100 \%$ & $97,78 \%$ & $97,78 \%$ \\
\hline $\begin{array}{l}\text { Menuliskan apa yang } \\
\text { perlu diketahui }\end{array}$ & 2 & 25 & 27 & 28 & $83,33 \%$ & $90 \%$ & $93,33 \%$ & $88,89 \%$ & $88,89 \%$ \\
\hline $\begin{array}{l}\text { Mengidentifikasi } \\
\text { masalah }\end{array}$ & 3 & 30 & 26 & 30 & $100 \%$ & $86,67 \%$ & $100 \%$ & $95,56 \%$ & $95,56 \%$ \\
\hline $\begin{array}{c}\text { Membuat rancangan } \\
\text { tindakan }\end{array}$ & $\begin{array}{l}4 \\
5 \\
6 \\
\end{array}$ & $\begin{array}{l}27 \\
26 \\
23\end{array}$ & $\begin{array}{l}30 \\
28 \\
25 \\
\end{array}$ & $\begin{array}{l}29 \\
27 \\
25\end{array}$ & $\begin{array}{c}90 \% \\
86,67 \% \\
76,67 \%\end{array}$ & $\begin{array}{c}100 \% \\
93,33 \% \\
83,33 \%\end{array}$ & $\begin{array}{c}96,67 \% \\
90 \% \\
83,33 \%\end{array}$ & $\begin{array}{c}95,56 \% \\
90 \% \\
81,11 \%\end{array}$ & $88,89 \%$ \\
\hline
\end{tabular}




\begin{tabular}{|c|c|c|c|c|c|c|c|c|c|}
\hline $\begin{array}{c}\text { Membuat penyelesaian } \\
\text { yang tepat }\end{array}$ & 7 & 28 & 23 & 30 & $93,33 \%$ & $76,67 \%$ & $100 \%$ & $90 \%$ & $85,55 \%$ \\
\hline
\end{tabular}

Dari tabel 3 dapat dilihat terdapat $97,78 \%$ siswa yang dapat menentukan fakta apa yang diketahui, $88,89 \%$ siswa dapat menentukan apa yang diketahui, 95,56\% siswa dapat mengidentidikasi masalah, 88,89\% siswa dapat membuat rancangan tindakan dan sebanyak 85,55\% siswa dapat membuat penyelesaian dengan tepat.

Berdasarkan indikator pertama, lebih dari 90 persen siswa dapat menuliskan fakta apa yang diketahui dari suatu masalah yang disajikan pada LKS seperti pada LKS 1diberikan suatu percobaan pembuatan telur asin dengan bahan-bahan yang telah disiapkan sebelumnya. Sebanyak 28 siswa dapat menuliskan semua fakta yang diketahui dari percobaan tersebut. Pada indikator menuliskan apa yang perlu diketahui, lebih dari 85 persen siswa dapat menuliskan apa saja fakta penting yang diperlukan untuk menjawab permasalahan yang diberikan. Sedangkan pada indikator mengidentifikasi masalah, lebih dari 95 persen siswa dapat menuliskan pokok permasalahan yang harus dipecahkan pada setiap kegiatan. Begitu juga pada indikator membuat rancangan tindakan. Meskipun tidak semua siswa dapat menuliskan langkah penyelesaian dengan tepat, namun hampir semua siswa dapat memetakan masalah dengan benar sehingga sebanyak 90 persen siswa sampai pada tahap kesimpulan secara mandiri.

\section{KESIMPULAN}

Setelah dilakukan analisis data berdasarkan LKS yang dikerjakan siswa dan observasi di lapangan saat siswa mengerjakan LKS didapat bahwa siswa dapat dengan mudah menuliskan faktafakta penting dari suatu masalah yang disajikan. Melalui LKS berbasis STEM yang diberikan siswa juga dapat menemukan keterkaitan antara bidang ilmu matematika dengan ilmu lainnya seperti sains sehingga siswa juga dapat melakukan pemetaan masalah dengan lebih tersusun. Dari analisis data yang dilakukan masih ada beberapa siswa yang kesulitan untuk membuat langkah penyelesaian dengan tepat juga beberapa siswa belum dapat membuat kalimat kesimpulan dengan benar, namun secara keseluruhan kemampuan pemecahan masalah siswa sudah diatas 80 persen.

Berdasarkan lima buah indikator tersebut dapat dirata-ratakan bahwa kemampuan pemecahan masalah siswa adalah 91,334\%. Dilihat dari kategori, kemampuan pemecahan masalah siswa tersebut dapat digolongkan Sangat Baik. Sehingga dapat disimpulkan bahwa kemampuan pemecahan masalah siswa setelah mengerjakan lembar kerja Sistem Persamaan Linier Dua Variabel berbasis STEM adalah Sangat Baik.

\section{DAFTAR PUSTAKA}

Arifin, Z., Trapsilasiwi, D., \& Fatahillah, A. (2016). Analisis Kemampuan Komunikasi Matematika Dalam Menyelesaikan Masalah Pada Pokok Bahasan Sistem Persamaan Linier Dua Variabel 
Siswa Kelas VIII-C SMP Nuris Jember. Jurnal Edukasi, 3(2), 9. https://doi.org/10.19184/jukasi.v3i2.3522

Bernard, M., Nurmala, N., Mariam, S., \& Rustyani, N. (2018). Analisis Kemampuan Pemecahan Masalah Matematis Siswa SMP Kelas IX Pada Materi Bangun Datar. SJME (Supremum Journal of Mathematics Education), 2(2), 77-83. https://doi.org/10.5281/zenodo.1405906

Cahyani, H., \& Setyawati, R. W. (2017). Pentingnya Peningkatan Kemampuan Pemecahan Masalah melalui PBL untuk Mempersiapkan Generasi Unggul Menghadapi MEA. Prosiding Seminar Nasional Matematika. https://journal.unnes.ac.id/sju/index.php/prisma/article/view/21635/10234

Djamilah, O., \& Widjajanti, B. (2009). Kemampuan Pemecahan Masalah Matematis Mahasiswa Calon Guru Matematika: Apa dan Bagaimana Mengembangkannya. In Seminar Nasional FMIPA UNY (Vol. 5). http://www.foxitsoftware.com

Farida, N. (2015). Analisis Kesalahan Siswa SMP Kelas VIII dalam Menyelesaikan Masalah Soal Cerita Matematika. AKSIOMA Journal of Mathematics Education, 4(2), 42-52. https://doi.org/10.24127/ajpm.v4i2.306

Handayani, K. (2017). Analisis Faktor - Faktor Yang Mempengaruhi Kemampuan Pemecahanmasalah Soal Cerita Matematika. Seminar Nasional Matematika (SEMNASTIKA) 2017.

Hidayat, W., \& Sariningsih, R. (2018). Kemampuan Pemecahan Masalah Matematis dan Adversity Quotient Siswa SMP Melalui Pembelajaran Open Ended. JNPM (Jurnal Nasional Pendidikan Matematika), 2(1), 109. https://doi.org/10.33603/jnpm.v2i1.1027

Ismayani, A., \& Pangeran Hidayatullah No, J. (2016). Pengaruh Penerapan STEM Project-Based Learning Terhadap Kreativitas Matematis Siswa SMK. Indonesian Digital Journal of Mathematics and Education, 3. http://idealmathedu.p4tkmatematika.org

Lathiifah, I. J., Zulkardi, Z., \& Somakim, S. (2015). Pengembangan Bahan Ajar Materi Aturan Pencacahan Menggunakan Pembelajaran Berbasis Masalah di SMA. Jurnal Didaktik Matematika, 2(2). http://www.jurnal.unsyiah.ac.id/DM/article/view/2817

Meutia, H., Johar, R., Ahmad, A., Pendidikan, M., Program, M., Unsyiah, P., Aceh, B., Keguruan, F., Pendidikan, I., Unsyiah, M., \& Unsyiah, P. (2013). Kemampuan Mahasiswa Calon Guru Menerapkan Penilaian Kinerja Untuk Menilai Hasil Belajar Siswa dalam Pembelajaran Matematika. Jurnal Peluang, 1(2). http://www.jurnal.unsyiah.ac.id/peluang/article/view/1059

Permanasari, A. (2016). STEM Education: Inovasi dalam Pembelajaran Sains. In Prosiding SNPS 
Analisis Kemampuan Pemecahan Masalah Siswa Pada Pembelajaran Spldv Berbasis STEM, Iis Juniati Lathiifah, Eka

(Seminar Nasional Pendidikan Sains) (Vol. 3, Issue 0$)$. http://jurnal.fkip.uns.ac.id/index.php/snps/article/view/9810

Siregar, N. R. (2017). Prosiding Temu Ilmiah X Ikatan Psikologi Perkembangan Indonesia Persepsi siswa pada pelajaran matematika: studi pendahuluan pada siswa yang menyenangi game. In Hotel Grasia (Vol. 1, Issue 0). www.pisaindonesia.wordpress.com

Sumartini, T. S. (2018). Peningkatan Kemampuan Pemecahan Masalah Matematis Siswa melalui Pembelajaran Berbasis Masalah. Mosharafa: Jurnal Pendidikan Matematika, 5(2), 148-158. https://doi.org/10.31980/mosharafa.v5i2.270

Wijayanti, D. (2020). Analisis Soal Pemecahan Masalah Pada Buku Sekolah Elektronik Pelajaran Matematika SD/MI. In Majalah Ilmiah Sultan Agung (Vol. 49, Issue 123). http://bse.depdiknas.go.id. 